\title{
LAS FALACIAS EN EL SERMÓN "EL DIEZMO” DE RADIO MARÍA
}

\author{
Dorde Cuvardic García \\ Adrián Vergara Heidke
}

\begin{abstract}
RESUMEN
En este artículo analizamos las falacias presentes en el sermón radiofónico "El diezmo" del Padre Minor de Jesús Calvo, a partir de las clasificaciones de la lógica clásica. Además, discutimos principios teóricos y metodológicos de la lógica no formal y de la tipología textual. Esto con miras a despertar el interés en el análisis de la argumentación desde un punto de vista pragmático y discursivo.

Palabras clave: análisis del discurso, falacia, sermón, tipología textual, lógica no formal.
\end{abstract}

\begin{abstract}
In this article we analyze the fallacies in the radiophonic sermon "El diezmo" of Father Minor de Jesús Calvo, based on classical logic classifications. Moreover, we discuss theoretical and methodological principles of non formal logic and textual typology with the purpose of encouraging the interest in the research of argumentation from a pragmatics and discourse analysis perspective.

Key words: discourse analysis, fallacies, sermon, textual typology, non formal logic.
\end{abstract}

\section{Introducción}

El ámbito religioso, en comparación con otras prácticas sociales, ha sido poco investigado por la comunicación y la lingüística (véase, por ejemplo, en el ámbito de la comunicación, a Hoover y Venturelli 1996; aunque ya existen intentos por ordenar las investigaciones realizadas, como en Stout y Buddenbaum 1996 ). Tal vez muchos analistas, dando por supuesto que el mundo occidental contemporáneo se encuentra desacralizado, le asignan muy poco interés.

Dorde Cuvardic García. Profesor de la Escuela de Filología, Lingüística y Literatura de la Universidad de Costa Rica. San Pedro, San José, Costa Rica.

Adrián Vergara Heidke. Profesor de la Escuela de Filología, Lingüística y Literatura de la Universidad de Costa Rica. San Pedro, San José, Costa Rica.

Recepción: 23-8-05

Aceptación: 8-9-05 
Sin embargo, se puede poner en entredicho este proceso de desacralización; podemos afirmar, en diagnóstico más preciso, que en estos dos últimos siglos se ha dado un proceso de secularización de las instituciones públicas.

Las instituciones religiosas y los medios de comunicación han sido considerados como espacios en conflicto: se afirma que los medios de comunicación han sustituido a la Iglesia como principal institución persuasiva de la sociedad occidental. Serían ámbitos completamente separados, no sólo en su finalidad, sino también en sus prácticas comunicativas y discursivas. Desde esta perspectiva, la Iglesia seguiría ejecutando procesos comunicativos cara a cara, sin hacer uso de la comunicación mediática. Los medios de comunicación de masas religiosos demuestran lo contrario: en Costa Rica, por ejemplo, la Iglesia, tanto la católica como la protestante, hacen amplio uso de los procesos comunicativos massmediáticos. En el territorio nacional, pueden escucharse las siguientes radioemisoras Sendas de vida (89.5 FM), Radio Mundial Adventista (difunde por satélite desde San José), Radio FIDES (93.1 FM - 1040 AM), Estereo Visión (98.3 FM), Faro del Caribe (97.1 FM) y La Paz del dial ${ }^{2}$ (100.3 FM), mientras que en televisión pueden sintonizarse los canales evangélicos Cristo Visión (Canal 31), Enlace TBN (Canal 23), Canal 35 (Enlace Juvenal), Family Christian Network (Canal 52) y la católica Telefides.

Por otra parte, la música pop se ha incorporado ampliamente al ritual religioso, no sólo protestante, sino también católico (desterrando a la tradicional música sacra), así como a las prácticas de recepción de algunos radioescuchas, situación que observamos cuando viajamos en taxi o en autobús. Ha aumentado en las últimas décadas el número de medios de comunicación religiosos. Además, Hoover y Verturelli (1996: 257-8) consideran que los medios de comunicación de masas contemporáneos, así como el orden social del que forman parte, son religiosos, en el sentido de que expresan y celebran valores, creencias y prácticas sacras. Una muestra es la amplia representación informativa otorgada a la muerte del Juan Pablo II y a la elección de Benedicto XVI, fundamentada más en la influencia que tiene la Iglesia Católica en los Estados occidentales o en su participación en el contenido de los sistemas de creencias de los ciudadanos que en la misma práctica religiosa cotidiana de estos últimos.

No puede negarse la influencia social de los medios de comunicación religiosos; por ejemplo, protagonizan la creación y mantenimiento de las alarmas sociales (moral panics, en inglés). Las actitudes hacia muchos asuntos sociales (tal como aparecen en las tendencias de las encuestas de opinión pública) pueden depender del éxito persuasivo de medios de comunicación religiosos o de medios de comunicación generalistas que incorporan 'valores morales' en sus noticias.

La capacidad movilizadora de los medios de comunicación religiosos en Costa Rica es grande en algunos grupos de población. Un ejemplo que viene a demostrar esta afirmación es el fenómeno mediático religioso de mayor impacto de los últimos años en Costa Rica: la actividad desplegada por la emisora Radio María de Guadalupe, dirigida y fundada por el Padre Minor Calvo desde 1999 hasta $2001^{3}$. Esta radioemisora llegó a ubicarse en el primer lugar de preferencia con un 9,6\% en el año 2000 y 7,3\% en 2001, según el Proyecto de Investigación Estructuras de la Opinión Pública, realizado por la Escuela de Matemática en el año 2003.

Esta emisora logró reunir mucho dinero de los feligreses radioyentes, meta que no se hubiera alcanzado si no hubiera desplegado una gran actividad persuasiva. Un ejemplo son los sermones de Radio María (sobre el noviazgo, sobre el diezmo), no sólo radiotransmitidos a los oyentes, sino también comercializados en cassettes. En estas circunstancias, el propósito de este artículo es analizar las falacias que, a través de un análisis preliminar, consideramos que aparecen en el sermón “El diezmo”, cuyo locutor es el Padre Minor Calvo. 


\section{El sermón}

\section{1. El sermón radiofónico}

Originalmente desarrollado cara a cara, el sermón constituye una práctica comunicativa y discursiva que ha sido adaptada al ámbito massmediático. Recordemos, junto con Demetrio Estébanez Calderón (1999: 979), que el sermón es una “(m)odalidad de la oratoria sagrada que se desarrolla en el marco de una celebración litúrgica y que tiene por objeto la explicación de aspectos doctrinales del dogma y de la moral, basados en la Biblia y en el magisterio de la Iglesia". El sermón es un texto que explica a los feligreses aspectos doctrinales del dogma cristiano ${ }^{4}$. Este carácter divulgativo se acomoda muy bien a la comunicación radiofónica: una de las claves de su éxito popular corresponde a la explicación, en lenguaje cotidiano, del discurso especializado.

\subsection{El sermón como texto argumentativo}

\subsubsection{Texto}

El concepto "texto" se puede entender de dos formas distintas, una abstracta y otra concreta. La primera se refiere al objeto teórico de la lingüística general, el cual se define por características internas como su textura (hechos microlingüísticos) y su estructura (hechos macrolingüísticos). Por su parte, el texto concreto alude al producto de un acto de enunciación, es decir, a un objeto real (físico, ya sea escrito u oral) determinado. El texto como abstracción puede ser tipologizable, ya que corresponde a un constructo, el cual posee cierto grado de homogeneidad; mientras que el texto concreto se caracteriza por su heterogeneidad, debido a la gran variedad de formas que puede adoptar.

Horst Isenberg (1983: 98) señala que es necesaria una tipología textual:

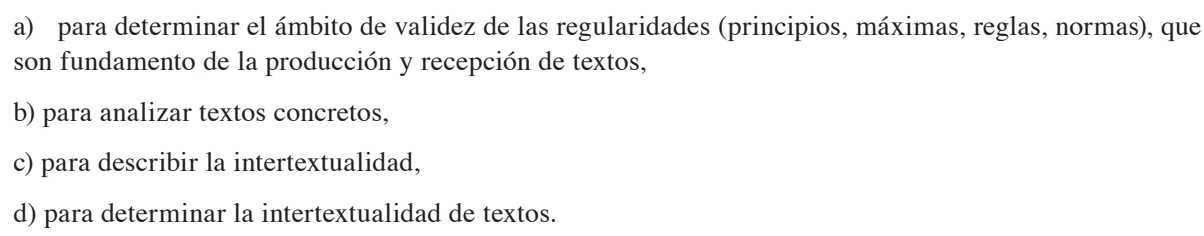

En relación con nuestro análisis, pretendemos situar el sermón dentro de un tipo de texto específico. Determinar la modalidad discursiva empleada en el sermón nos permitirá conocer tanto las intenciones de sus productores como las interpretaciones que buscan promover en sus oyentes.

\subsubsection{Secuencia}

A continuación, se expondrá la tipología textual propuesta por Casamiglia y Tusón (1999), la cual sigue los planteamientos de Jean-Michel Adam (2000).

Esta tipología se basa en el concepto de secuencia propuesto por Adam (1999: 62):

La unidad textual que designamos como SECUENCIA se presenta, por una parte, como una red de relaciones jerárquicas -puede descomponerse en partes (ORACIONES) unidas entre ellas (PROPOSICIONES) y unidas al todo que constituyen (SECUENCIA)- y, por otra parte, como entidad relativamente autónoma. Está dotada de organización interna propia y mantiene una relación de dependencia / independencia con el conjunto más amplio del que forma parte: el TEXTO. 
Los textos contienen un número indefinido de secuencias, las cuales, por lo general, no son homogéneas, sino heterogéneas. La tipología se establece según la secuencia dominante y se divide en cinco tipos de textos o modos de organización secuencial: la narración, la descripción, la argumentación, la explicación y el diálogo.

\subsection{La argumentación}

El sermón es un texto y, como tal, incorpora diferentes modos de organización secuencial, aunque podemos expresar la siguiente afirmación preliminar: la argumentación domina sobre los demás. ¿Por qué podemos considerar inicialmente que el sermón “El diezmo” es un texto argumentativo? Si "(1)a argumentación se hace necesaria cuando alguien no está de acuerdo con una opinión (interpretación, prueba, posición, conclusión)” (Bassols y Torrent 1996: 31) y si "(s)e argumenta (...) en cualquier situación en la que se quiere convencer o persuadir de algo a una audiencia" (Casamiglia y Tusón 1999: 294), el sermón que nos ocupa se dedica a convencer a aquellos feligreses reacios a dar el diezmo a que lo ofrezcan con regularidad. El sermón sobre el diezmo responde a la función apelativa, conativa, ya que va dirigido a un 'otro', buscando su adhesión.

Siguiendo a Casamiglia y Tusón, las características de la argumentación serían:

a) Objeto: cualquier tema controvertido, dudoso, problemático, que admite diferentes maneras de tratarlo. Se puede formular como pregunta.

b) Locutor: ha de manifestar una manera de ver e interpretar la realidad, una toma de posición. Expone la opinión a través de expresiones modalizadas y axiológicas.

c) Carácter: polémico, marcadamente dialógico; se basa en la contraposición de dos o más posturas (verdades o creencias aceptadas o posiciones defendidas por un sector o por una persona). Los enunciados se formulan en relación con otros enunciados efectivos o virtuales. Se manifiesta, implícita o explícitamente, la oposición, el contraste, la desautorización, el ataque, la provocación...

d) Objetivo: provocar la adhesión, convencer, persuadir a un interlocutor o a un público de la aceptabilidad de una idea, de una forma de ver el tema que se debate.

Jean-Michel Adam (2000: 157) propone la siguiente secuencia argumentativa prototípica $^{5}$ :

\begin{tabular}{|c|c|c|c|c|c|}
\hline $\begin{array}{l}\text { Tesis } \\
\text { Anterior } \\
\text { P. arg. } 0\end{array}$ & 1 & $\begin{array}{l}\text { Datos } \\
\text { (premisas) } \\
\text { P. arg. } 1\end{array}$ & $\begin{array}{l}\text { Apoyo de } \\
\text { las } \\
\text { inferencias } \\
\text { P. arg 2 }\end{array}$ & $\begin{array}{l}\text { por lo tanto } \\
\text { probablemente }\end{array}$ & $\begin{array}{l}\text { Conclusión } \\
\text { (Nueva) } \\
\text { Tesis } \\
\text { P. arg. } 3\end{array}$ \\
\hline
\end{tabular}

a menos que

Restricción

P. arg. 4

Figura 1. Secuencia argumentativa prototípica 
En todo texto argumentativo existe, por lo menos, una posición contraria (o diferente) a la que defiende el locutor, que corresponde a una tesis anterior explícita o implícitamente planteada. Los datos (premisa menor) constituyen una proposición que justifica una conclusión. Ahora bien, el paso de un dato a una conclusión se da gracias al apoyo de las inferencias (premisa mayor), para ser precisos, a una regla de inferencia que correspondería a un "razonamiento subyacente que tendría la estructura de un silogismo" (Adam 2000: 144). Este silogismo puede estar expresado o ser compartido por el auditorio (topos).

La secuencia argumentativa prototípica "no es de un orden lineal inmutable" (Adam 2000: 157), ya que, por ejemplo, una conclusión puede servir de apoyo de las inferencias (premisa mayor) o dato (premisa menor) de otra secuencia relacionada. Por último, en un texto cabe la posibilidad de que se presenten secuencias interrelacionadas y otras completamente autónomas.

\subsection{2. ¿Es el sermón sobre el diezmo un texto argumentativo?}

A continuación, procederemos a analizar si este sermón corresponde a un texto argumentativo.

En primer lugar, observamos los atributos de este tipo de textos en el sermón que nos ocupa:

-Su objeto consiste en el pago del diezmo. Los subtemas ${ }^{6}$ tratados se enmarcan en el tema global, deber u obligación de pagar el diezmo. Además, el título ${ }^{7}$ del sermón programa su interpretación por los oyentes: "El diezmo". El tributo del diezmo históricamente ha sido discutido (tema controversial) en el interior de la Iglesia Católica, en relación con dos puntos principales: su obligatoriedad, ya que en la Biblia se encuentran fragmentos que argumentan tanto a su favor como en su contra, lo que lleva a diferentes interpretaciones y valoraciones; y a la utilización del dinero recibido, ya que muchos contribuyentes (católicos) no tienen acceso a los informes sobre el empleo de estos donativos.

-El locutor toma una posición o punto de vista sobre el tema, el cual consiste en que las personas deben pagar el diezmo, ya que ese dinero le pertenece a Dios. Este posicionamiento se expresa lingüísticamente por medio de diferentes recursos. Algunos ejemplos de éstos son:

a) ...voy a compartir / un mensaje / desde la palabra / de Dios...

b) ...yo creo que...

c) ...usted se equivoca...

d) ...deberá / admitir que...

e) ...probablemente nunca antes / lo había visto desde este punto de vista...

Aparece explícitamente un punto de vista en los ejemplos a) y $e$ ), mientras que en $b$ ), por medio de una modalización (verbo creer), se señala una postura. Finalmente, en $c$ ) y $d$ ) se apela al oyente para que se dé cuenta de lo errada que está la tesis contraria y, en cambio, preste atención a la corrección de la propia.

-El texto posee un carácter opositivo dialógico. Es un texto opositivo porque el locutor se contrapone con su posición al punto de vista de las personas que consideran el dinero 
que ganan (producen) como suyo (“...yo lo produje / a mí me pertenece...”); mientras que es dialógico porque el emisor se dirige hacia el posible oyente a través de diferentes recursos lingüísticos: uso de pronombres (“...lo que usted gana...”), preguntas retóricas (“...¿no fue usted quien lo produjo?...”), vocativos (“"hermanos...”), conjugación de verbos en modo imperativo (“...dé el diezmo...”), entre otros.

-El objetivo es convencer al oyente de que todo feligrés debe pagar el diezmo. Al leer el objeto del texto, la posición del locutor y el carácter, sumado a la secuencia prototípica y al análisis de las falacias (ambos aspectos presentados a continuación), nos parece innecesario profundizar más sobre el objetivo, ya que tendremos que repetir y anticipar ejemplos en respaldo de lo señalado.

En cuanto a la secuencia (ver Fig. 1) predominante ${ }^{8}$ del texto analizado, concuerda con la secuencia argumentativa prototípica; encontramos una tesis anterior expresa, varios datos, diferentes apoyos de las inferencias, tanto explícitos como implícitos y, por último, conclusiones.

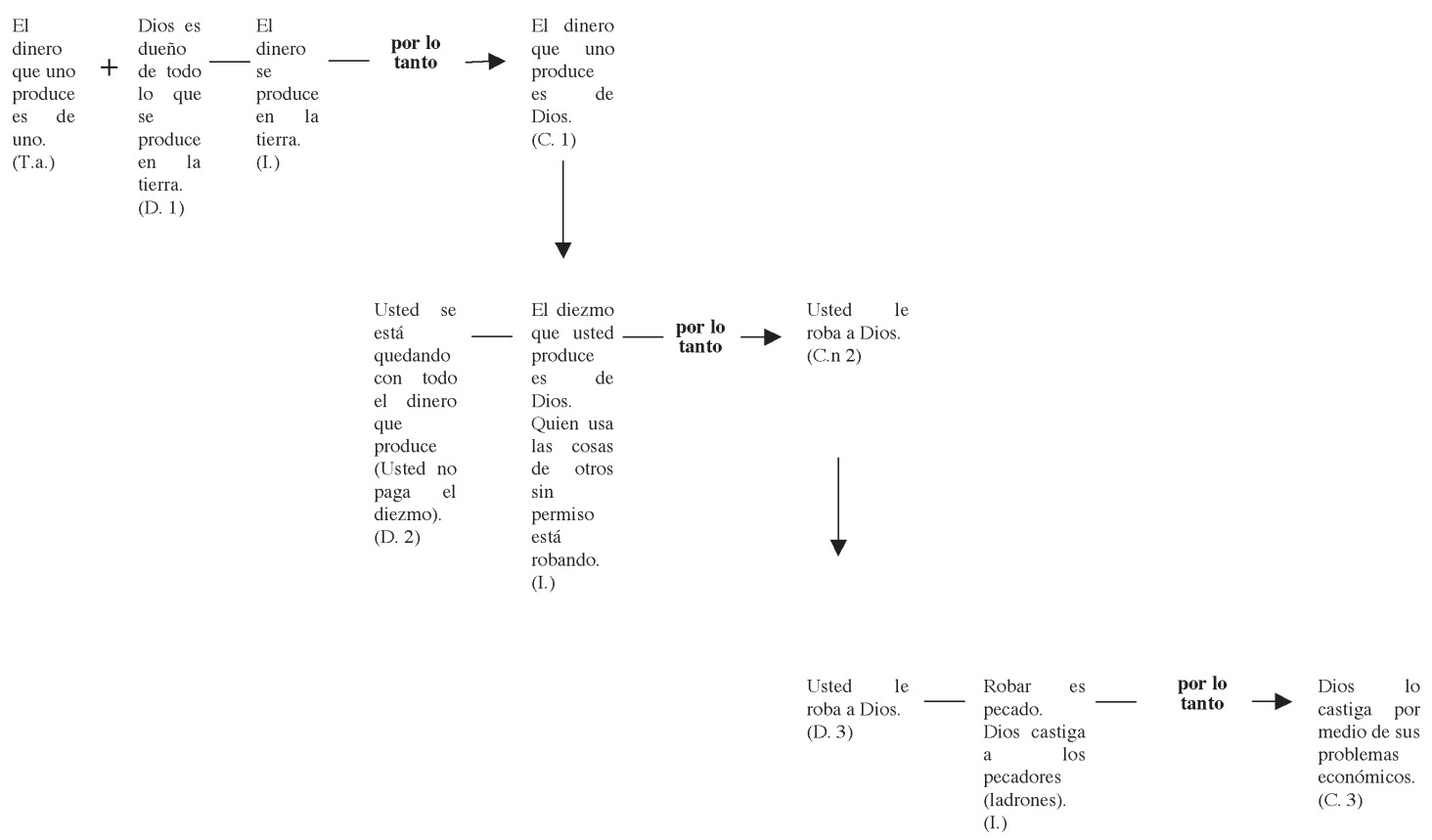

Figura 2. Secuencia ${ }^{9}$ predominante del sermón "El diezmo".

\subsection{El sermón "El diezmo"}

El proceso argumentativo de este sermón queda estructurado desde un marco interpretativo o enmarque comercial: se construye el vínculo entre Dios y sus feligreses como un trato o compromiso de carácter comercial: “...de hecho / la ley de Dios / tocante a lo que usted gana es en realidad / un trato...". 
El exordio ${ }^{10}$ de este sermón ya establece desde el inicio el marco interpretativo desde el que serán construidos los argumentos y desde el que estos últimos serán comprendidos por los oyentes. El Padre Minor se presenta ante sus oyentes como intermediario de Dios, como representante y difusor de la Palabra de Dios: "Hermanos // voy a compartir hoy / un mensaje / desde la palabra / de Dios...”. Si Dios, según el Padre Minor, plantea a los creyentes un pacto económico, él se arrogará el papel de intermediario comercial de un proyecto mercantil propuesto por la divinidad y desconocido hasta ahora por los feligreses. Ya señaló Curtius (1998: 133) que uno de los tópicos del exordio, durante la Edad Media, fue plantear que el que posee conocimientos debe divulgarlos. El Padre Minor considera que tiene conocimientos todavía ignorados por los feligreses que deben ser divulgados. En realidad, plantea argumentos en los que se incorporan bastantes falacias, según analizamos a continuación.

\section{Falacias}

\subsection{Definición de falacia}

Una falacia es una forma de razonamiento incorrecta o inválida, aunque parezca válida o correcta (Camacho 2000: 117; Copi 1984: 81). En este artículo analizaremos las falacias no formales, aquellas que se encuentran en los discursos cotidianos (Camacho 2000: 118), presentes en un sermón radiofónico sobre el diezmo difundido por el Padre Minor Calvo a través de Radio María. Las falacias no formales se clasifican en falacias de atinencia o atingencia y en falacias de ambigüedad, distinción seguida tanto por Camacho como por Copi.

\subsection{Análisis de las falacias del sermón "El diezmo"}

En este apartado definimos, presentamos e interpretamos las falacias presentes en el sermón "El diezmo". En algunas ocasiones diversos tipos de falacias pueden quedar imbricadas en un mismo enunciado.

Tradicionalmente ${ }^{11}$ se distinguen dos grandes grupos de falacias no formales: las de atingencia y las de ambigüedad (lingüísticas, anfibológicas o de claridad). Las primeras se dan por el parecido entre la conclusión no atingente (la que se presenta en una falacia) y la que se seguiría válidamente (Camacho 2000: 119); es decir, no se establece una relación lógica entre premisas y conclusiones (Copi 1984: 83). En cambio, en las de ambigüedad, "la conclusión válida no se obtiene debido a algún fallo en el lenguaje” (Camacho 2000: 119); en otras palabras, aparecen por causas linguiísticas, particularmente, semánticas (Copi 1984: 104) y gramaticales.

\subsubsection{Falacias de atingencia}

Las falacias de inatingencia surgen cuando un argumento cuyas conclusiones no son consecuencia de premisas previas es interpretado como razonamiento estructuralmente válido. Copi (1984: 83) considera que las falacias de inatingencia se distinguen porque "sus premisas carecen de atinencia lógica con respecto a sus conclusiones" (en cursiva en el original), mientras que Camacho (2000: 119) las caracteriza como aquellas en las que "la conclusión no atingente -es decir, que no se sigue de las premisas- parece seguirse porque se parece a la conclusión que se seguiría válidamente.” Se dan en la relación estructural entre premisas y conclusión. 
¿Qué favorece, ante el auditorio, el ocultamiento de las falacias de atingencia como razonamientos inválidos o incorrectos? Copi (1984: 83) afirma que en algunos casos provocan actitudes que favorecen su aceptación. La ausencia de atingencia lógica queda oculta ante su alta eficacia persuasiva, psicológica. La eficacia emotiva oculta su incorrección argumentativa.

\title{
3.2.1.1. Falacia de llamado al pueblo
}

La falacia de llamado al pueblo permea todo el sermón "El diezmo". Aparece cuando el orador recurre a aquellas afirmaciones o conclusiones no demostradas mediante pruebas que presupone capaces de despertar aceptación general (Camacho 2000: 123; Copi 1984: 89). El orador justifica la entrega del diezmo por parte del feligrés para que la humanidad alcance una situación deseada por el oyente: nadie quiere ser pobre. A continuación, presentamos un ejemplo:

\begin{abstract}
...¿ipara qué quiere Dios ese primer décimo? // ¿en qué lo utiliza? // él requiere esa pequeña fracción // de lo que se produce o extrae de su tierra / para diseminar entre las naciones / su mensaje / ACERCA / del camino de vida / que les dará gozo y éxito y vida eterna // si aún / ese décimo / que el eterno retiene para su uso // se emplea / en el bien DE LA HUMANIDAD / compréndalo hermano / para proclamar el evangelio de paz / de felicidad / de gozo y de salvación // para librar al hombre de toda clase de dificultades // para que no haya pobres // Dios no quiere pobres / los pobres / los que carecen de hasta lo indispensable para la vida / lo son / por causa del egoísmo / la INJUSTICIA / la GUERRA / la ENFERMEDAD / EL APROVECHAMIENTO DE AQUELLOS / QUE CADA VEZ SON MÁS RICOS / en una sociedad a veces muy injusta donde el pobre cada vez es más pobre...
\end{abstract}

\subsubsection{Falacia de causa falsa}

En el sermón aparecen bastantes falacias de causa falsa. Este tipo de falacia se presenta cuando el orador instiga a tomar una situación como causa de un acontecimiento o de un efecto simplemente porque es temporalmente previa, o cuando instiga a tomar como causa total lo que sólo es causa parcial (Camacho 2000: 130-1; Copi 1984: 93-4). A continuación, presentamos tres ejemplos:

\footnotetext{
...usted tiene que asociarse a Dios / ¿por qué me va tan mal en los negocios? / ¿por qué ando alcanzado con el pago de la luz / del agua? / ¿por qué no tengo para un par de zapatos? / ah un momentito / es que usted está / haciendo las cosas mal / y por eso usted siempre es un pobre / usted siempre anda pidiendo prestado / usted siempre anda pellizcando..

...¿NO prospera usted en sus negocios? // ¿está endeudado? // ¿está atrasado económicamente? // su infidelidad en pagar a Dios su diezmo // bien puede ser la razón...

...¿¿cómo no va a tener un montón de deudas más // si usted la primer deuda la tiene con Dios?...
}

La estructura argumentativa de las falacias precedentes se asemeja: el apoyo de las inferencias (premisa mayor) plantea Es preciso asociarse a Dios para salir de la pobreza; el dato (premisa menor) lo constituye El radioyente no se asocia a Dios; luego, la conclusión, El radioescucha no podrá salir de la pobreza. Se presenta una falacia de causa falsa, pues la asociación con Dios no es causa necesaria ni suficiente para salir de la pobreza.

El sermón presenta variaciones de la falacia de causa falsa en el tema de la pobreza. Otro ejemplo es el siguiente: 


\begin{abstract}
...Dios no quiere pobres // y oiga // lo que hacen los que no siguen la ley de Dios / en su afán de ayudar a los pobres / y a los que viven en la miseria / crean instituciones que se financian / con dineros // sucios // a base de impuestos a las cosas / y medios que fomentan la corrupción de seres humanos / licor / cantinas // prostíbulos / moteles / pornografías / drogas // esos dineros son malditos // esa es la razón que antes usted nunca antes había oído / del porqué esas instituciones / HUMANAS / NO LOGRAN / NO SON CAPACES / DE REALIZAR SUS OBJETIVOS / por más positivos que sean / porque sus dineros no son dineros SANOS / muchos dineros con que se ayuda a instituciones / de beneficencia / son dineros venidos de impuestos / de casas de corrupción / hablémoslo / MUY / MUY / claro...
\end{abstract}

\title{
3.2.1.3. Falacia de conclusión inatingente
}

Aparece la falacia de conclusión inatingente cuando en un razonamiento cuyas premisas se dirigen a establecer una conclusión específica se introduce una conclusión diferente (Camacho 2000: 120; Copi 1984: 97):

... todas las leyes de Dios fueron hechas / para / EL / BIEN / DEL / HOMBRE / la obediencia / a estas leyes / espirituales / SIGNIFICA BENDICIONES / cuando violamos dichas leyes / solamente nos acarreamos maldiciones...

No existe ningún apoyo inferencial (premisa mayor) que demuestre que la falta de seguimiento a las leyes divinas acarree maldiciones, desgracias, consecuencias negativas... Además, se presenta en el enunciado mencionado una falacia de apelación a la fuerza, a tratar un poco más abajo. El feligrés debe obedecer leyes espirituales cuyo "quebrantamiento" conllevará consecuencias negativas.

Aparece otra falacia de conclusión inatingente en el siguiente enunciado. Enunciado que cuenta con algunas variante en el sermón, se asume una conclusión de una condición previa que no es necesaria ni suficiente para que tenga lugar:

... el hombre que paga al Creador / su décima parte es un hombre PRÓSPERO...

El Padre Minor emplea el término prosperidad desde un marco interpretativo económico. Evidentemente, la prosperidad económica de los ciudadanos, incluso como feligreses, no proviene del pago del diezmo.

\subsubsection{Falacia de petición de principio}

La falacia de petición de principio se comete cuando se toma como premisa del razonamiento, repitiéndola de manera solapada, la conclusión que se pretende probar (Camacho 2000: 129; Copi 1984: 94). Aparece a lo largo de todo el sermón cuando se afirma reiteradamente que "el feligrés debe entregar el diezmo" sin apoyarse en premisas previas (aunque en otras ocasiones apoya esta conclusión en su condición de mandato de Dios): como la falacia de petición de principio adquiere su eficacia persuasiva por medios psicológicos, parece que el orador ofrece apoyos argumentativos a la afirmación que realiza, cuando en realidad está planteando la misma conclusión con otras palabras. 
En la cita previa se repite tres veces la afirmación: el dinero que gana el feligrés no es suyo (implícitamente, es de Dios). La primera vez se plantea como pregunta retórica, con la respuesta correspondiente:

...ं̈ंes realmente suyo el dinero que usted gana? // no esté tan seguro...

En la segunda y cuarta ocasiones se presenta como afirmaciones explícitas:

...que usted gana / no le pertenece...

...lo que usted gana mediante su trabajo / o mediante / inversiones hechas // no es suyo / ni siquiera la más mínima porción de ello...

La tercera vez, como afirmación implícita (si se equivoca el hombre que dice que el dinero que gana le pertenece, implícitamente se infiere que no le pertenece, que Dios será su propietario):

...se equivoca el hombre que dice / lo que yo haga con el dinero que gano // por mi propio esfuerzo / no es asunto de nadie / yo lo produje / a mí me pertenece...

\subsubsection{Falacia de apelación a la fuerza}

El orador comete la falacia de apelación a la fuerza cuando amenaza con represalias como recurso para que la audiencia acepte una conclusión o afirmación (Camacho 2000: 128; Copi 1984: 83). En el siguiente extracto, después de plantear una falacia de conclusión inatingente (sustentada en citas procedentes de la Biblia), se ejerce presión para que sea respaldada la propuesta del orador por la audiencia mediante una falacia de apelación indirecta a la fuerza.

\footnotetext{
...el salmista dice / del Eterno / es la tierra y cuanto la llena / el mundo / y los que en él habitan / porque él la fundó sobre los mares / y la afirmó sobre los ríos / Salmo veinticuatro uno // estas inspiradas palabras se repiten en Corintios // porque la tierra y todo lo que contiene / es / del / Señor / todo lo que hay / debajo del cielo / es mío / afirma Dios / en el Libro de Job // he aquí / del Eterno / tu Dios / son los Cielos // y / los Cielos de los Cielos / la tierra / y todas las cosas que hay en ella / MÍA es toda la tierra / Éxodo diecinueve / si yo tuviera hambre / dice Dios el creador / no te lo diría a ti / porque mío es el mundo // y todo lo que contiene // porque mía es toda / bestia / del bosque / y los millares de animales en los collados // sí / también el dinero / aún el oro y la plata / MÍA ES LA PLATA / Y MÍO EL ORO / DICE / EL ETERNO DE LOS EJÉRCITOS / a través del profeta ageo // ¿se atreve / hombre alguno // a desmentir tales reclamaciones de Dios? / pues éstas en efecto / gústenle o no al hombre / son leyes / espirituales / INEXORABLES // usted deberá / admitir / que sus ingresos // pertenecen a Dios / hermano / se lo REPITO / sus ingresos le pertenecen a Dios // son de él / y él puede disponer de ellos a su entera libertad....
}

El padre Minor presenta como hecho lo que es una simple opinión y, además, ordena su aceptación a la audiencia con la amenaza indirecta "...¿ise atreve / hombre alguno // a desmentir tales reclamaciones de Dios?...". Se presupone que el atrevimiento será castigado. Ya destacan Van Eemeren y Grootendorst (2002: 129) que las amenazas se emiten generalmente de manera indirecta. Un procedimiento utilizado en la construcción de la falacia de apelación a la fuerza de carácter indirecto es plantear que las maldiciones no caerán sobre nadie en particular, sino sobre la colectividad. La responsabilidad por esta 'falta' es colectiva, no individual

También se formula indirectamente una amenaza en un enunciado citado en un apartado precedente de este artículo: 
...todas las leyes de Dios fueron hechas / para / EL / BIEN / DEL / HOMBRE / la obediencia / a estas leyes / espirituales / SIGNIFICA BENDICIONES / cuando violamos dichas leyes / solamente nos acarreamos maldiciones...

Otra amenaza velada o indirecta aparece en la siguiente falacia:

...cuando el hombre / descuida / enfrentar / ése décimo / o entregar ese décimo / ¿verdad? // roba a su socio

/ que es Dios / y por ende // quién sabe / si las bendiciones // continuarán de igual manera...

Primero, se presenta una falacia personal ofensiva. El feligrés que no entrega el diezmo es un ladrón. Incluso en otra parte del sermón se compara a este tipo de feligrés con Caín: "somos como Caín". Pero frente al punto de vista del Padre Minor, desde la doctrina de la Iglesia un feligrés que no entregue el diezmo no es ladrón. Es falaz afirmar o establecer que la acción de no entregar el diezmo es un delito, incluso ante Dios.

Esta falacia personal ofensiva va acompañada de una amenaza. El ladrón (es decir, la persona que no entregue el diezmo) obtendrá maldiciones de Dios. Se presenta en el enunciado mencionado una falacia de apelación a la fuerza. El feligrés debe obedecer leyes espirituales cuya omisión conllevará consecuencias negativas.

\subsubsection{Falacia de pregunta compleja}

La falacia de pregunta compleja se presenta cuando se formula una pregunta que presupone una respuesta, por lo general afirmativa, a una pregunta anterior por parte del interlocutor (Camacho 2000: 132; Copi 1984: 95).

En este sermón se utiliza en diversas ocasiones la llamada pregunta retórica, cuyo empleo no da lugar necesariamente a la formulación de una falacia de pregunta compleja. Como parte de su estrategia didáctica, el Padre Minor, teniendo en cuenta a un oyente implícito, formula preguntas que su auditorio realizaría. Ahora bien, en una pregunta retórica puede aparecer una falacia de pregunta compleja. Así sucede cuando el Padre Minor indaga en las causas de la pobreza del costarricense (inmediatamente después la establecerá en el hecho de eludir el pago del diezmo); es decir, asume que el costarricense, en general, vive en situación de pobreza. La pobreza del costarricense es una premisa que debe reiterar el Padre Minor a la hora de proponer la entrega del diezmo como superación de este estado.

\footnotetext{
... ¿por qué me va tan mal en los negocios? / ¿por qué ando alcanzado con el pago de la luz / del agua? / ¿por qué no tengo para un par de zapatos?...

...¿NO prospera usted en sus negocios? // ¿está endeudado? // ¿está atrasado económicamente? // su infidelidad en pagar a Dios su diezmo // bien puede ser la razón...

¿cómo no va a tener un montón de deudas más // si usted la primer deuda la tiene con Dios?...
}

\subsubsection{Falacias de ambigüedad}

Mientras que las falacias de inatingencia se identifican al analizar la estructura del argumento, las de ambigüedad tienen carácter semántico. Aparecen en cambios intencionadamente sesgados en el significado de frases o palabras utilizadas en la argumentación (Camacho 2000: 132; Copi 1984: 104). 


\subsubsection{Falacia de equívoco}

Se incurre en la falacia de equívoco cuando se utiliza en un enunciado un término de múltiples sentidos sin establecer una definición específica de este (Camacho 2000: 132-3; Copi 1984: 105).

...el hombre que paga al Creador / su décima parte es un hombre PRÓSPERO...

Este enunciado no sólo formula una falacia de conclusión inatingente, sino también una falacia de equívoco: se asume que el Creador no sólo es Dios, sino también la Institución eclesiástica y cada uno de sus miembros. Se presupone el siguiente enunciado: "El feligrés que paga a Radio María su décima parte es un hombre próspero".

\footnotetext{
...yo sé que en la Iglesia / no se nos ha enseñado a diezmar // se nos ha enseñado / A TRATAR A DIOS DE LIMOSNERO // ¿cómo dicen los sacerdotes equivocadamente la Iglesia? // hermanos / vamos a recoger / LA / LIMOSNA // sí // la última moneducha / la más sucia / y el billetillo más arrugado / echáselo a Dios / somos como Caín // Caín tuvo maldición / y todo se le arruinó // sus empresas y negocios / porque Caín / de lo más feo / que tenía de los frutos / se lo regalaba a Dios / en cambio Abel / dice la Biblia / le daba a Dios lo mejor / y entró en prosperidad / yo sé que nos ha enseñado / y lo digo como sacerdote / los hemos enseñado a ustedes mal / el sólo hecho de decir / den limosna / ¿QUIÉN DIJO QUE DIOS ES UN LIMOSNERO? / Dios no tiene porqué recibir limosna / Dios tiene que recibir la parte que le toca...
}

En este ejemplo se juega con dos acepciones del término "limosna": a) "Dinero u otra cosa que se da por caridad" (Moliner, Tomo II, 1999: 189); y b) "Cantidad (de dinero) que se da (...) que, por ser muy pequeña o insuficiente, parece más bien una limosna” (189). La primera acepción es utilizada por los religiosos durante la misa, aclarando que por "caridad" se entiende "(v)irtud que la Iglesia define como amor a Dios sobre todas las cosas y al prójimo como a nosotros mismos" (Moliner, Tomo I, 1999: 528); la otra acepción es utilizada por los castellanohablantes en la comunicación cotidiana referido al (poco) dinero que se entrega a ciertos individuos necesitados (pobres), principalmente, a indigentes. Se puede observar que el Padre Minor sólo usa la segunda acepción, que no corresponde a la utilizada por los sacerdotes de quienes habla. Esta interpretación que realiza el Padre Minor queda reforzada por su uso de la palabra "limosnero", cuya acepción más recurrente en el lenguaje coloquial es: "mendigo" (Moliner, Tomo II, 1999: 189). El locutor busca apoyo a su argumentación (falaz): a la hora de perfilar a su oyente implícito, prevé que los feligreses aceptarán que a Dios no se le entreguen limosnas, que Dios no es ningún mendigo o indigente, ni que se lo trate como tal.

\subsubsection{Falacia de composición ${ }^{12}$}

El orador incurre en la falacia de composición cuando, en un razonamiento, se asumen como atributos de un todo el atributo de alguna de sus partes, o cuando se asumen como atributos de una clase los atributos de alguno de sus miembros (Camacho 2000: 135; Copi 1984: 109-110). Las actitudes racistas, xenófobas, sexistas, homófobas, se expresan en opiniones que incurren en la falacia de composición: el comportamiento de un miembro se generaliza al grupo al que la sociedad le 'asigna'. Combatir estas actitudes implica combatir la utilización de la falacia de composición en contextos intolerantes. Por otra parte, debe distinguirse la falacia de composición del empleo de la sinécdoque, tan empleada en el lenguaje cotidiano.

En el sermón que nos ocupa, se presentan dos ejemplos ${ }^{13}$ de este tipo de falacia: 
a) El caso del señor Colgate:

Este señor comenzó a pagar el diezmo desde niño y llegó a ser un hombre millonario, dueño de una famosa empresa.

b) El caso del señor de Escazú14.

Un señor de Escazú estaba muy mal económicamente; sin embargo, un padre le dijo un día que pagara el diezmo y así lo hizo; con el tiempo se convirtió en uno de los hombres más ricos de Costa Rica.

El locutor considera que todos, a los que les va bien económicamente, pagan el diezmo. Esta argumentación constituye una falacia, ya que no todas las personas a las que les va bien económicamente pagan el diezmo, ni tampoco son católicas ${ }^{15}$.

\footnotetext{
...todas las personas curiosamente que / diezman / hasta el día de hoy / no conozco una sola / que tenga que decirme // padre // nosotros / estamos arruinados...
}

El locutor establece la siguiente generalización: a todas las personas que comiencen a pagar el diezmo necesariamente les irá bien en lo económico. Además, aparece la falacia de causa falsa: la relación causal entre pagar el diezmo y buena situación económica no ha sido comprobada.

\section{Conclusiones}

El marco interpretativo utilizado por el Padre Minor para que el oyente comprenda los argumentos propuestos en este sermón radiofónico es el comercial. Podemos concluir preliminarmente que se utiliza este marco interpretativo en el discurso religioso como consecuencia de su éxito persuasivo o, por lo menos, de su amplia utilización, en las más diversas prácticas sociales contemporáneas. Las instituciones religiosas, incluida la Iglesia Católica, no quieren quedarse atrás en su uso. Los actuales analistas del discurso investigan la difundida presencia de enmarques o encuadres económicos y financieros en la estructuración de los discursos públicos contemporáneos, ya sean políticos, gubernamentales, religiosos, deportivos. Chilton y Schäffner (2000: 318-20), por ejemplo, analizan las metáforas del ámbito del marketing emitidas en un discurso de John Major en un congreso del Partido Conservador Británico. Los analistas del discurso llegan a la siguiente conclusión: el discurso político ha quedado en los últimos años imbuido de los valores del discurso neoliberal. En este último, se utilizan como premisas mayores, jerarquías de valores: la universalidad de los servicios sociales queda subordinada a la eficacia presupuestaria; la justicia social, a la 'libre' competencia para imponer la ley del más fuerte... Los argumentos presentados por el Padre Minor se rigen por los mismos valores: sobre todo, se apela al diezmo como fuente de enriquecimiento personal (son escasos los ejemplos sobre la ayuda que puedan aportar los diezmos a las comunidades).

Al inicio definimos el sermón como un texto que explicaba a los feligreses aspectos doctrinales del dogma cristiano. Es decir, en un principio, podríamos respaldar el punto de vista de la Iglesia Católica: el sermón es un texto expositivo. Y lo sería según la tipología de Jean-Michel Adam: este tipo de textos consisten en plantear un hacer saber (educar) y en un hacer comprender y aclarar (divulgar). Como sucede con todo texto divulgativo (el periodístico de carácter científico también se encuentra entre este último), se presupone un 
conocimiento que, en principio, no se cuestiona, sino que se toma como punto de partida. Sin embargo, en nuestro análisis demostramos que, aunque el Padre Minor ofrezca sus afirmaciones como verdades indiscutibles, no deja de respaldarlas con apoyos argumentativos: plantea falacias, trata de refutar argumentos contrarios. El sermón sobre el diezmo cuenta con todas las características de un texto argumentativo, por lo cual no respaldamos la definición previa que se otorga al género del sermón, es decir, como texto expositivo, por lo menos en el caso que nos ocupa. Cabe preguntarse si nuestra concepción del sermón como texto argumentativo se puede generalizar, aunque se necesitan más investigaciones de este tipo para formular tal afirmación.

Además, el Padre Minor pretende convencer para movilizar a la acción. Busca persuadir al oyente para que emprenda cierto comportamiento: pretende adoctrinar a los feligreses en las leyes de la Iglesia para que estos últimos den el diezmo. Esta es la finalidad del sermón y de las falacias propuestas en este último. Como acto de habla directivo, siguiendo la terminología de John Searle, ejecutado en el ámbito de la invitación, se propone al final del discurso la entrega del diezmo a la Institución Católica (y a Radio María como parte de esta institución):

\footnotetext{
...le invito / a dar el diezmo // y si usted quiere / hacerlo / a esta PLATAFORMA DE EVANGELIZACIÓN / y dar el diezmo a esta plataforma / hermanito mío // usted puede venir a Radio María / y vamos a hacer un libro de / diez man tes / si quiere lo hace a través del banco / cuenta / de Banco Nacional / doscientos nueve / ciento cuarenta y seis / guión cero / Radio María // o si quiere personalmente / viene a entregar / especificado / diezmo // de / cada // sueldo / de cada entrada que usted tiene // recuerde que el diezmo / no hay donde perderse y enredarse / es el diez por ciento...
}

En este sermón aparecen bastantes falacias no formales de atingencia, y muy pocas falacias no formales de ambigüedad. Se puede extraer una falacia principal. Se trata de una falacia de conclusión inatingente: el pago del diezmo conlleva el enriquecimiento del donante.

Nuestro análisis se basó en una comprensión lógica de las falacias, desde la cual un argumento es inválido "porque la conclusión no se sigue de las premisas" (Camacho 2000: 119). Desde esta postura teórica, el sentido de un enunciado se extraería del léxico utilizado; de hecho, a partir de estos elementos se establece la distinción entre falacias de atingencia y las de ambigüedad (establecida tanto por Copi como por Camacho), ya que en las primeras no habría dudas sobre su sentido (el problema radicaría sobre la relación argumento-conclusión), mientras que en las otras, sí. Este lineamiento nos parece reduccionista, por cuanto desconoce que el sentido de un enunciado depende no sólo de aspectos semánticos, sino que también de gramaticales, pragmáticos y discursivos. Además, considera lo dicho explícitamente, dejando fuera del análisis todo lo implícito, lo cual puede tener, incluso, más relevancia en el momento de la argumentación y en el momento de la persuasión.

A partir de lo anterior, creemos que se debe profundizar en la investigación de la argumentación desde una perspectiva pragmática y discursiva, que no olvide todos los aspectos que participan en la producción e interpretación de los textos.

\section{Notas}

1. Se han realizado sobre todo análisis de contenido cuantitativos tanto de medios de comunicación religiosos como generalistas. En el primer caso, se ha investigado, por ejemplo, circunscribiéndonos al ámbito estadounidense, el carácter político de la televisión religiosa de este país (Abelman y Pettey 1988), así 
como el carácter religioso de la programación de la televisión religiosa (Abelman y Neuendorf 1985); en el segundo caso, se ha analizado la representación informativa de la religión en la prensa escrita (Buddenbaum 1986; Hynds 1987).

2. Antigua Radio María de Guadalupe.

3. Desde diciembre de 2003, el Padre Minor de Jesús Calvo se encuentra procesado como sospechoso en el caso de la muerte del periodista Parmenio Medina, el cual hizo varias denuncias públicas contra la administración de Radio María.

4. Aunque no es objeto de análisis en este artículo, recordemos que los predicadores y los sermones también han sido objeto tradicional de análisis a través de la sátira, tanto clerical como seglar, desde la cual se somete esta práctica discursiva a un análisis retórico. Sólo en el segundo caso, desde la sátira seglar, se llegará algunas veces al anticlericalismo.

Los dos tipos de sátira con más larga tradición en Occidente son la política y la religiosa. En el ámbito de la sátira religiosa se han criticado las arbitrariedades de los eclesiásticos. El sermón se ha constituido en un vehículo idóneo para presentar estas arbitrariedades humanas como Ley de Dios. En este sentido, no es de extrañar que los sermones y los predicadores se hayan convertido en blanco de ataque la sátira, como es el caso del Padre Francisco de Isla con su Fray Gerundio de Campazas. En esta novela no sólo se criticó el uso de lenguaje barroquizante en los sermones de algunos predicadores del siglo XVIII, sino también el uso del púlpito para el enriquecimiento personal. Véase un análisis de este último aspecto en Chen (1999). Marchese y Forradellas (1997: 374) también nos recuerdan que "(s)e da también el nombre de sermones a algunas composiciones poéticas, casi siempre burlescas, que imitan la estructura del sermón religioso: así, por ejemplo, el Sermón de Amores de Castillejo.”

5. "P." abrevia a "procedimiento", es decir, P.arg. 0 significa procedimiento argumentativo 0.

6. En el presente artículo no se hará una exposición de la progresión temática del texto, sin embargo, ésta se puede observar en la reconstrucción de las falacias y de su secuencia predominante.

7. Somos concientes de que el título de un texto no necesariamente corresponde al tema del mismo, pero en esta ocasión sí concuerdan tema y título.

8. Estamos agrupando en una secuencia compleja (Fig. 1) las principales secuencias argumentativas del texto; sin embargo, cabe señalar que se presentan otras que no consideramos, ya que nuestro objetivo en esta parte consiste en demostrar que el sermón es un texto argumentativo, con el fin de, posteriormente, analizar en profundidad sus falacias.

9. Simbología de Fig. 1: T.a. significa Tesis anterior; D., Dato; I., Apoyo de las inferencias; y C., Conclusión.

10. Es la parte inicial del discurso, orientada a predisponer al auditorio a una atención favorable (Marchese y Forradellas (1997: 156).

11. Estudios retóricos, argumentativos y lógicos.

12. Copi señala que se presentarían falacias de generalización apresurada (o accidente inverso) cuando "consideramos casos excepcionales y generalizamos apresuradamente una regla que se adecua a ellos solamente" (1984: 93). Sin embargo, Camacho (2000) no las presenta en su clasificación de las falacias no formales; esto se debería, quizás, a su semejanza con las falacias de composición, en las cuales a 
partir de los atributos de una parte se generaliza para el todo. Nosotros seguiremos la postura de este último autor, por cuanto no observamos una diferencia clara entre las falacias de generalización apresurada, presentadas por Copi, y las de composición.

13. Presentaremos un resumen de cada ejemplo, ya que ambos son muy extensos.

14. Así se lo identifica.

15. Ni de otras religiones, en las cuales también se pague el diezmo.

\section{Bibliografía}

\section{Libros y revistas}

Abelman, Robert y Gary Pettey. 1988. "How political is religious television?". Journalism Quarterly. 65 (2), 313-9 y 359.

Abelman, Robert y Kimberly Neuendorf. 1985. "How religious is religious television programming?", Journal of Communication. 35 (1).

Adam, Jean-Michel y Clara Ubaldina Lorda. 1999. Lingüística de los textos narrativos. Barcelona: Ariel.

Adam, Jean-Michel y Marc Bonhomme. 2000. La argumentación publicitaria. Retórica del elogio y de la persuasión. Madrid: Editorial Cátedra.

Bassols, Margarita, Ana M. Torrent. 1996. Modelos textuales. Teorías y práctica. Barcelona: Eumo/Octaedro.

Billings, Dwight B. y Shaunna L. Scott. 1994. "Religion and political legitimation", Annual Review of Sociology. 20, 173-201.

Bernárdez, E. (comp.). 1987. Teoría y epistemología del texto. Madrid: Cátedra.

Buddenbaum, Judith M. 1986. "An analysis of religion news coverage in three major newspapers", Journalism Quarterly. 63 (3), 600-6.

Camacho, Luis. 2000. Introducción a la lógica (Segunda edición). Cartago: Editorial Tecnológica de Costa Rica.

Casamiglia, Helena y Amparo Tusón. 1999. Las cosas del decir. Barcelona: Ariel.

Chilton, Paul y Cristina Schäffner. 2000. "Discurso y política”. En: Teun A. van Dijk (comp.). El discurso como interacción social. Barcelona: Editorial Gedisa.

Copi, Irving M. 1984. Introducción a la lógica. Buenos Aires: Editorial Universitaria de Buenos Aires. 
Curtius, Ernst Robert. 1998. Literatura europea y edad media latina. México: Fondo de Cultura Económica.

Goode, Erich y Nachman Ben-Yehuda. 1994. "Moral panics: culture, politics, and social construction", Annual Review of Sociology. 20, 149-71.

Hoover, Stewart M. y Shalini S. Venturelli. 1996. "The category of religious: the blindspot of contemporary media theory?", Critical Studies in Mass Communication. 13 (3), 251-65.

Hynds, Ernest C. 1987. "Large daily newspapers have improved coverage of religion", Journalism Quarterly. 64 (3): 444-8.

Isenberg, Horst. 1987. "Cuestiones fundamentales de tipología textual”. En: E. Bernárdez (comp..), 95-129. Madrid: Cátedra.

Marchese, Angelo y Joaquín Forradellas. 1997. Diccionario de retórica, crítica y terminología literaria. Barcelona: Editorial Ariel.

Moliner, María. 1999. Diccionario de uso del español. Tomo I y II. Segunda edición. Madrid: Gredos.

Perelman, Ch. y L. Olbrechts-Tyteca. 1989. Tratado de la argumentación. La nueva retórica. Madrid: Editorial Gredos.

Stout, Daniel A. y Judith M. Buddenbaum. 1996. "Introduction. Toward a synthesis of mass communication research and the sociology of religion". En: Religion and mass media. Audience and adaptations. Thousand Oaks: Sage Publications, 3-11.

Sullivan, Patricia A. 1995. "A relational approach to moral decision-making: the majority opinion in Planned Parenthood v. Casey”, Quarterly Journal of Speech. 81: 167-90.

Van Eemeren, Frans H. y Rob Grootendorst. 2002. Argumentación, comunicación y falacias. Chile: Santiago.

Venegas, René. 2005. "Hacia una identificación automatizada de rasgos argumentativos en corpus". Discurso especializado e instituciones formadoras. Editor Giovanni Parodi. Valparaíso: Ediciones Universitarias de Valparaíso.

\section{Casete}

Calvo Aguilar, Minor de Jesús (Pbro.). (?). "El diezmo". Predicaciones. Radio María de Jesús. Casete adquirido en las instalaciones de la radioemisora. 


\section{Anexo núm. 1}

\section{Sermón sobre el diezmo}

hermanos // voy a compartir hoy / un mensaje / desde la palabra / de Dios // y comienzo estaaa predicación / haciendo una pregunta // ¿puede / un hombre / robar a Dios? // lo que la mayoría de la gente ignora // con toda seguridad / hay algo / que usted no sabe / acerca de sus ingresos // si / hay algo / que a los hombres / les toque el corazón // es / tocarles / el dinero / que ganan / yo creo que ahí es donde todo el mundo ¿verdad hermanito? / se echa para atrás y dice / ¡ay! el dinero / el punto clave de todo / generalmente // trabajan duro para obtenerlo / y quieren tener plena libertad / para decidir / por sí mismos / lo que [verían] hacer con él / o lo que deben hacer con él / lo que yo gano / es mío / puedo hacer con él // lo que me da la gana / dicen / pero / ¿es realmente suyo el dinero que usted gana? // no esté tan seguro // lo que usted gana / no le pertenece // se equivoca el hombre que dice / lo que yo haga con el dinero que gano // por mi propio esfuerzo / no es asunto de nadie / yo lo produje / a mí me pertenece // lo que usted gana mediante su trabajo / o mediante / inversiones hechas // no es suyo / ni siquiera la más mínima porción de ello / es decir / no lo es / sino hasta que / y precisamente / hermano / en eso consiste // lo que la mayoría de las personas no conocen acerca de sus ingresos // existen dos reclamaciones previas // que están / en torno a sus ingresos / una por supuesto / son las contribuciones o los impuestos decretados por el gobierno / que hay que pagarlos / en justicia / como lo manda la Iglesia / pero // HAY UNA RECLAMACIÓN QUE ES ANTERIOR A LA DEL GOBIERNO / por extraño que parezca / hay un poder activo / y viviente / que lo reclama todo / cada dólar / cada colón / cada peso / que usted obtiene // pero / ¿acaso / no lo ganó usted? // ¿no fue usted quien lo produjo? // no precisamente / todo lo que es producido / incluyendo el dinero / y todo lo que este puede proporcionar / proviene de la tierra / usted no produjo la tierra / fue el SER SUPREMO / DIOS / QUIEN LA CREÓ / veamos qué dice la Biblia / sobre quién es el dueño de la tierra // el salmista dice / del Eterno / es la tierra y cuanto la llena / el mundo / y los que en él habitan / porque él la fundó sobre los mares / y la afirmó sobre los ríos / Salmo veinticuatro uno // estas inspiradas palabras se repiten en Corintios // porque la tierra y todo lo que contiene / es / del / Señor / todo lo que hay / debajo del cielo / es mío / afirma Dios / en el Libro de Job // he aquí / del Eterno / tu Dios / son los Cielos // y / los Cielos de los Cielos / la tierra / y todas las cosas que hay en ella / MÍA es toda la tierra / Éxodo diecinueve / si yo tuviera hambre / dice Dios el creador / no te lo diría a ti / porque mío es el mundo // y todo lo que contiene // porque mía es toda / bestia / del bosque / y los millares de animales en los collados // sí / también el dinero / aún el oro y la plata / MÍA ES LA PLATA / Y MÍO EL ORO / DICE / EL ETERNO DE LOS EJÉRCITOS / a través del profeta ageo // ¿se atreve / hombre alguno // a desmentir tales reclamaciones de Dios? / pues éstas en efecto / gústenle o no al hombre / son leyes / espirituales / INEXORABLES // usted deberá / admitir / que sus ingresos // pertenecen a Dios / hermano / se lo REPITO / sus ingresos le pertenecen a Dios // son de él / y él puede disponer de ellos a su entera libertad // sin embargo / Dios es amor // él conoce sus necesidades // se interesa y se preocupa por usted // él no es egoísta no lo quiere todo para él // tiene en mente / sus mejores intereses y su bienestar / por tanto / ÉL HA CREADO UNA LEY / para regular aquella porción / de los bienes de él / en la que usted ha trabajado // invertido sus esfuerzos / y aplicado sus ideas // grábese esto bien en la mente / su paga / su salario / sus ganancias / sus ingresos / PERTENECEN A DIOS / HERMANO QUE ME ESTÁ ESCUCHANDO / quiera // sea quien sea usted // y quiera // que sea el lugar en que trabaje // 
usted que me está escuchando / TUS INGRESOS PERTENECEN A DIOS / probablemente nunca antes / lo había visto desde este punto de vista / debe parecerle una nueva idea / pero no es una idea / es un hecho / Dios es dueño de todo aquello en lo que usted trabaja / y aquello que con su participación / es producido / usted no podría producir nada sin la materia que Dios creó / sin hacer uso de las leyes las fuerzas y las energías / que él puso en movimieeento / y que aún sustenta // por tanto / Dios tiene derecho a tomar y a disponer / a su entera voluntad / aún de lo que usted considera su salario // él es el dueño // legítimo // de sus ingresos // hizo una ley / respecto al uso y distribución / de los mismos // en virtud / de ser el creador / y sustentador de la tierra / y todo cuanto hay en ella / Dios es el regente / y el legislador supremo / de hecho / la Ley de Dios / tocante a lo que usted gana es en realidad / un trato / mire que interesante / vamos a hacer un negocio con Dios hermanos // un trato / que Dios hace con usted // él le permite trabajar en la tierra de su propiedad // y Dios te da la vida / para que lo puedas hacer // te da los instrumentos los dones las cualidades // para que puedas utilizar / UNA PARTE / de ésta // a lo que // Dios // quiere // pero / de acuerdo // a lo que usted // necesita // usted podrá extraer del suelo comestibles materiales // metales maderas // elaborar sobre lo que otros han extraído de la tierra / manufacturas / distribución / inversión / compra venta / según sea su ocupación / a cambio de algo / y así / y aunque no lo haya comprendido antes / usted trabaja // a partir de hoy si usted quiere // en sociedad con Dios // la mayoría de personas // son socios de Dios / pero nunca le dan a Dios la parte que le toca a Dios / y hermanito / esa es la torta / y ahorita se lo voy a explicar porqué / hay un reclamo bíblico / que nuestro pueblo no conoce / nuestro pueblo católico / nuestro pueblo cristiano // y hoy vamos a hablar de eso / usted tiene que asociarse a Dios / ¿por qué me va tan mal en los negocios? / ¿por qué ando alcanzado con el pago de la luz / del agua? / ¿por qué no tengo para un par de zapatos? / ah un momentito / es que usted está / haciendo las cosas mal / y por eso usted siempre es un pobre / usted siempre anda pidiendo prestado / usted siempre anda pellizcando // de hecho / mi amado // hermano // usted // ¿quiere trabajar en sociedad con Dios? // el agricultor podrá sembrar la semilla / labrar la tierra // y expender / SU / LABOR / en hacer crecer productos alimenticios / pero ¿quién creó / los procesos de vida que hacen a la semilla germinar? / ¿quién envía la lluvia? / ¿quién hace que la planta absorba los minerales? / ¿acaso realizó usted / esa parte del crecimiento de los productos? / ¿de dónde viene todo? / ¿de dónde viene todo / sino / de la creación de Dios? / cuando nos detenemos a considerar estas cosas / vemos que el creador / suministra aproximadamente / EL NOVENTA POR CIENTO DE TODO LO QUE EL HOMBRE PRODUCE / y las ideas del hombre sus planes y su trabajo / suplen parte de las ganancias // él / Dios / ni siquiera // se toma un ochenta / ni un setenta / ni un treinta / ni un veinte por ciento / de lo que le toca / Dios es generoso // se reserva para su uso solamente / UNA PEQUEÑA / DÉCIMA PARTE / de lo que se produce o se extrae de la tierra / mediante la energía y las fuerzas que él creó / Dios toma solamente / UNA / DÉCIMA / PARTE / y ha decretado que después de que usted pague / con toda honradez / la pequeña décima parte que él pide // le sean otorgados a usted // los nueve décimos restantes / a partir de entonces / son suyos / para que los emplee / como mejor a usted le convenga // ponga a Dios a prueba // ¿para que quiere Dios ese primer décimo? / ¿en qué lo utiliza? / él requiere esa pequeña fracción // de lo que se produce o extrae de su tierra / para diseminar entre las naciones / su mensaje / ACERCA / del camino de vida / que les dará gozo y éxito y vida eterna // si aún / ese décimo / que el eterno retiene para su uso // se emplea / en el bien DE LA HUMANIDAD / compréndalo hermano / para proclamar el evangelio de paz / de felicidad / 
de gozo y de salvación // para librar al hombre de toda clase de dificultades // para que no haya pobres // Dios no quiere pobres / los pobres / los que carecen de hasta lo indispensable para la vida / lo son / por causa del egoísmo / la INJUSTICIA / la GUERRA / la ENFERMEDAD / EL APROVECHAMIENTO DE AQUELLOS / QUE CADA VEZ SON MÁS RICOS / en una sociedad a veces muy injusta donde el pobre cada vez es más pobre / si aunque usted // no lo haya oído antes // Dios no quiere pobres // sí hermano // Dios no quiere miserables // Dios no quiere gente / que está viendo a ver cómo se las agencia / para el día siguiente / por lo menos tener un poquitico de café / Dios no quiere pobres // y oiga // lo que hacen los que no siguen la ley de Dios / en su afán de ayudar a los pobres / y a los que viven en la miseria / crean instituciones que se financian / con dineros // sucios // a base de impuestos a las cosas / y medios que fomentan la corrupción de seres humanos / licor / cantinas // prostíbulos / moteles / pornografías / drogas // esos dineros son malditos // esa es la razón que antes usted nunca antes había oído / del porqué esas instituciones / HUMANAS / NO LOGRAN / NO SON CAPACES / DE REALIZAR SUS OBJETIVOS / por más positivos que sean / porque sus dineros no son dineros sanos / muchos dineros con que se ayuda a instituciones / de beneficencia / son dineros venidos de impuestos / de casas de corrupción / hablémoslo / MUY / MUY / claro // el mundo necesita de este conocimiento con urgencia / el mundo vive bajo una maldición / porque ha estado // robaaando a Dios / todo su dinero / y su / ri que za / y con ello / se ha despojado a sí mismo / de la posibilidad de saber / porqué // la vida parece hueca y vacía / llena se sufrimiento / frustración / muerte hambre // todas las leyes de Dios fueron hechas / para / EL / BIEN / DEL / HOMBRE / la obediencia / a estas leyes / espirituales / SIGNIFICA BENDICIONES / cuando violamos dichas leyes / solamente nos acarreamos maldiciones // el hombre que paga al Creador / su décima parte es un hombre PRÓSPERO // con ello no quiero decir / hermanos // que necesariamente sea rico y poderoso // sino que es un individuo / a quien le es suministrado / todo aquello / que realmente necesita // Dios ha prometido que sus hijos tendrán siempre algo que dar // y nunca se presentarán el Señor / con las manos vacías // ofrecerán / cada uno // su don // según la bendición / que les haya dado el Señor // solamente cuando ellos retienen y se apropian el primer décimo / deja el de hacerlos prosperar // por medio del Apóstol San Pablo él nos dice / yo deseo que tu prosperes / en todas las cosas / y que tengas salud / tercera carta de San Juan versículo dos / HONRA A Dios con tus riquezas / CON LA PRIMERA PARTE DE TUS GANANCIAS / y SERÁN / llenos tus graneros / con abundancia / Y TUS LAGARES / REBOSARÁN de mosto / proverbios tres / nueve // haga usted la prueba / probadme ahora en esto / nos dice Malaquías tres diez // así nos desafía Dios / el Dios de los ejércitos / pónganme a prueba / Malaquías tres diez // si no abriré las ventanas de los cielos y vaciaré / sobre / vosotros / bendición hasta que sobreabunde / ¿NO prospera usted en sus negocios? // ¿está endeudado? // ¿está atrasado económicamente? // su infidelidad en pagar a Dios su diezmo // bien puede ser la razón // usted le paga al Ice el teléfono // usted le paga / al instituto de electricidad / la electricidad que usted consume / usted paga a Acueductos y Alcantarillados el impuesto del agua / usted paga a Tributación Directa lo que hay que pagar / pero usted nunca le paga a Dios la parte de Dios / ¿no será ésta la razón por la que usted anda / tan alcanzado / y anda tan mal / arruinado económicamente / y es un POBRETE / de quien todo el mundo se burla? // una pequeña historia como ejemplo // se cuenta que el señor Colgate // ¿han oído hablar / dee la pasta Colgate? / ese / es un apellido / Colgate es un apellido // MUNDIALMENTE como fabricante de pastas famoso / abandonó el hogar ese señor / cuando era un muchachillo de corta edad // en breve conoció a un próspero / capitán de marina // el 
capitán preguntó al jovencito // qué sabía hacer // él dijo / sé hacer jabones y velas // somete a Dios / le aconsejó / el viejo marinero / somete a Dios tus planes / págale / la décima parte de tus entradas / algún día habrá algún gran hombre a la cabeza / de una importante industria jabonera / en Nueva York / y no hay razón alguna / para que ése / no llegues a ser tú // el muchacho aceptó el consejo // consiguió trabajo / ganó un dólar / y pagó diez centavos para promover el Evangelio // después ganó / dos dólares / y pagó veinte centavos // pronto obtuvo trabajo / en una fábrica de jabón / y continuó pagando la décima parte de sus ingresos / y prosperando // se elevó de obrero común a funcionario / más tarde fue ascendido a gerente // y finalmente / se hizo dueño de todo el establecimiento // viendo que continuaba prosperando // el señor Colgate empezó a pagar dos diezmos // prosperó aún más / y pagó tres // luego y finalmente / su prosperidad aumentó a nivel mundial / la famosa internacional Colgate / a tal grado // que decidió dar la mitad de todos sus ingresos / y AÚN ASÍ / continuó prosperando / le pagó a Dios la parte que le tocaba a Dios // Dios es su socio hermano / si usted quiere // un individuo decidió hacer a Dios su socio en todos sus negocios / y le daba una décima parte de cuanto ganaba // pero este individuo / cometió un grave error // no somos nosotros los que hacemos a Dios / socios / en los negocios / es cierto // por el contrario / es DIOS / quien desde el principio // hizo a todo ser humano su socio // Dios pide un décimo / y nosotros nos quedamos con nueve décimos // pero Dios es su socio / muy exigente // si usted descuida pagar el primer diezmo / a Dios / tal como él lo ordena / usted es culpable de robar // cada moneda // de diez céntimos // de cada colón // y cada diez colones / de cada cien // y cada cien colones / de mil colones // y cada mil colones / de diez mil // y cada diez mil / de cien mil // y cada cien mil / de un millón // mi querido hermano // eso / no es suyo // y si usted se lo deja o lo está usando en otra cosa // permítame decirle la palabra / clave / usted sería un ladrón / de Dios / ¿puede un hombre // robarle a Dios? / perfectamente / nada de eso es suyo / usted no sólo robó el diezmo / que descuidó pagar // robó los diez décimos // eso es fraude / eso es robo // como usted ve // nada de lo que es producido / o extraído de la tierra del creador // viene a ser suyo / sino hasta que / con toda honestidad / usted pague a Dios el diezmo requerido // DIOS ES SU SOCIO / ES DUEÑO DE LA TIERRA / ASÍ COMO DE LOS PODERES / Y ENERGÍAS QUE HAY EN ELLA / ÉL LE PERMITE EN TANTO TRABAJE COMO SU SOCIO / LABORAR EN LA TIERRA DE SU PROPIEDAD / Y UTILIZAR SU FUERZAS Y ENERGÍAS Y PODERES / bajo el convenio de / que // él recibe el primer décimo / y luego le es dado a usted el resto / es decir / los otros nueve décimos // cuando el hombre / descuida / enfrentar / ése décimo / o entregar ese décimo / ¿verdad? // roba a su socio / que es Dios / y por ende // quién sabe / si las bendiciones // continuarán de igual manera // hay una profecía para hoy // la verdadera Iglesia está fundada sobre los apóstoles y los profetas // es la Iglesia que Cristo edificó / y de la cual DIOS HIZO A CRISTO LA CABEZA // uno de los profetas sobre los cuales está fundada la Iglesia / o profecías / es Malaquías // escuchemos esta enseñanza profética / que forma parte íntegra del Nuevo Testamento / DESDE LOS DÍAS / de vuestros padres / os habéis apartado de mis leyes / y no las guardasteis // malditos sois / con maldición // porque vosotros la nación todas // me pertenecen / pero me han ROBADO / pero / ¿por qué? / ¿qué ha traído esta maldición nacional / de preocupaciones / en materia de finanzas / en casi todos los hogares? // ¿por qué es que a nadie / parece alcanzarle el dinero // y andan / en unas / carreras / tremendas? // Dios dice / que es // porque / le HEMOS ROBADO // y dijisteis / continúa el mensaje de Dios // ¿en qué te hemos robado? / y Dios responde / en VUESTROS DIEZMOS Y OFRENDAS / Malaquías tres ocho / Cristo Jesús personalmente inculcó la ley del diezmo / finalmente 
observemos el ejemplo personal de Jesús / quién es la cabeza de su ministerio hoy día // hablando con los escribas y fariseos / quienes frecuentemente hacían alarde de justicia / y de guardar estrictamente / uno de los pequeños puntos de la ley de Dios / Jesús dijo // ay de vosotros escribas y fariseos HIPÓCRITAS / porque pagáis el diezmo de la menta del comino // y dejáis lo más importante de la ley / la justicia y la misericordia // esto era necesario hacer sin dejar de hacer aquello // pagar cuidadosamente los diezmos // con todo lo dicho // muchos dicen / no creo que sea muy razonable / el que yo pague el diezmo / mientras tenga deudas // el DIEZMO ES LA DEUDA / QUE USTED TIENE CON DIOS // una deuda mi querido hermano que ocupa EL PRIMER LUGAR // ¿cómo no va a tener un montón de deudas más // si usted la primer deuda la tiene con Dios? // buscad primero el reino de Dios / y todo lo demás vendrá por añadidura / hermano // únase a Dios // ASÓCIESE A DIOS // Y USTED A PARTIR DE HOY / VERÁ ENSANCHADA LAS PUERTAS ECONÓMICAS DE SU FAMILIA DE SU EMPRESA / Y DE TODOS SUS ASUNTOS ECONÓMICOS / hermano / ¿le gustaría ser socio? / usted pregunta // ¿y adónde va el diezmo? // usted lo puede hacer / SI QUIERE / aquí a la plataforma de evangelización de radio María // porque lo que aquí entra / se utiliza para evangelizar // y se utiliza / en el Ministerio / que pronto tendrá radio María / el buen samaritano / para ayudar a los pobres // se va a canalizar el diezmo que va a dar // en dos rubros // uno / evangelización / que es lo que está haciendo radio María / ya casi ya veinticuatro horas / y el otro rubro es / de los pobres // hermano // ¿quiere seguirle usted robando a Dios? // piénselo muy bien // diez colones de cada cien // cien de cada mil // no son suyos // le pertenecen a Dios / y usted tiene que / devolverle a Dios lo que le ha quitado // pida a Dios que le ayude // y de ahora en adelante dé el diezmo / usted dirá / ¿cómo voy a dar / de mi pobre sueldo cincuenta mil pesos por mes / cómo voy a dar cinco mil? / hermano / es que precisamente en eso consiste el diezmo / ¿qué usted tiene dudas? // hágalo // ¿qué tiene deudas? // hágalo // ¿qué usted cree que le va a ir peor? / hermano / pruebe a Dios / dé el diezmo // yo sé que en la Iglesia / no se nos ha enseñado a diezmar // se nos ha ensañado / A TRATAR A DIOS DE LIMOSNERO // ¿cómo dicen los sacerdotes equivocadamente la Iglesia? // hermanos / vamos a recoger / LA / LIMOSNA // sí // la última moneducha / la más sucia / y el billetillo más arrugado / echáselo a Dios / somos como Caín // Caín tuvo maldición / y todo se le arruinó // sus empresas y negocios / porque Caín / de lo más feo / que tenía de los frutos / se lo regalaba a Dios / en cambio Abel / dice la Biblia / le daba a Dios lo mejor / y entró en prosperidad / yo sé que nos ha enseñado / y lo digo como sacerdote / los hemos enseñado a ustedes mal / el sólo hecho de decir / den limosna / ¿QUIÉN DIJO QUE DIOS ES UN LIMOSNERO? / Dios no tiene porqué recibir limosna / Dios tiene que recibir la parte que le toca // y bíblicamente ya ha quedado demostrado / que la parte de Dios / es el diez por ciento / ¿qué usted gana cien mil por mes? / diez mil son de Dios // vaya y délos a donde usted quiera / si no lo quiere dar a Radio María // no importa / pero vaya y délos a un sacerdote y dígale // padre de mi parroquia / estos diez mil pesos / como el diezmo / recíbalos // recíbalos / porque esto tiene que ser de Dios / y padre / no me quiero dejar un dinero que más bien me traiga ruina y maldición // todas las personas curiosamente que / diezman / hasta el día de hoy / no conozco una sola / que tenga que decirme // padre // nosotros / estamos arruinados // en Paso Ancho desde hace dos años / el pueblo de Paso Ancho diezma // y es pobre Paso Ancho // y por el diezmo // se están alimentando cualquier cantidad de familias pobres / y se está sirviendo a la evangelización // y nadie / nadie / ha tenido que decir / por diezmar / todo lo contrario / Paso Ancho está prosperando / porque están diezmando / allá en Escazú / el testimonio del padre Howell / que recoge el diezmo / 
una comunidad próspera // un día llegó un señor en ruina / en total ruina / y le dijo al padre / ayúdeme padre / yo soy licenciado en no sé cuánto en no sé qué / y resulta padre / que yo / me estoy quedando en la ruina / no consigo trabajo // lo único que ando aquí son cien miserables pesos // ah anda cien colones / hágame el favor y vaya / a la caja del diezmo / y eche diez colones // porque es la parte de Dios // dice el padre Walter que el señor se asustó y dijo / qué bruto este sacerdote / tras de que quiero ayuda / todavía me pide / de lo poquitillo que tengo / sin embargo en su capricho / el señor lo hizo / al día siguiente / el señor consiguió trabajo // al mes llegó donde el sacerdote y le dijo / padre // de lo que me comenzó a entrar / comencé a devolverle a Dios el diez por ciento de eso // y hoy vengo a agradecerle padre // porque la prosperidad / volvió a mi casa // dice el padre / que años más tarde / se encontró al señor otra vez // y es uno de los hombres / más ricos de este país // mire qué maravilla // después de ser un / un / ARRUINADO ZAPATOS ROTOS / ¿usted cree que Dios quiere que estemos en miseria? // ¿usted cree que Dios está contento con ver gente empobrecida? // usted me dirá padre / yo soy tan pobre que ni tengo / cien pesos para dar de los mil que tengo // DÉSELOS A DIOS / DÉSELOS // dé el diezmo // y las bendiciones // los graneros suyos esto es // sus negocios // se van a aumentar // porque quien lo promete / lo cumple / y el que lo promete no engaña / se llama / el Dios eterno / dueño del cielo y la tierra / le invito / a dar el diezmo // y si usted quiere / hacerlo / a esta PLATAFORMA DE EVANGELIZACIÓN / y dar el diezmo a esta plataforma / hermanito mío // usted puede venir a Radio María / y vamos a hacer un libro de / diez man tes / si quiere lo hace a través del banco / cuenta / de Banco Nacional / doscientos nueve / ciento cuarenta y seis / guión cero / Radio María // o si quiere personalmente / viene a entregar / especificado / diezmo // de / cada // sueldo / de cada entrada que usted tiene // recuerde que el diezmo / no hay donde perderse y enredarse / es el diez por ciento // que Dios les bendiga // vamos ahorita a un cortecito / y ya / regresamos / a las llamadas telefónicas / para compartir el tema del diezmo esta mañana ...

[00:26:02]

Simbología

I : pausa breve (centésimas de segundo)

// : pausa ( un segundo)

[ ] : palabra no muy clara

MAYÚSCULAS: mayor intensidad 